\title{
Spared unconscious influences of spatial memory in diencephalic amnesia
}

\author{
Albert Postma $\cdot$ Rémy Antonides · Arie J. Wester • \\ Roy P. C. Kessels
}

Received: 20 August 2007/Accepted: 1 June 2008/Published online: 17 June 2008

(C) The Author(s) 2008

\begin{abstract}
Spatial memory is crucial to our daily lives and in part strongly depends on automatic, implicit memory processes. This study investigates the neurocognitive basis of conscious and unconscious influences of object-location memory in amnesic patients with Korsakoff's syndrome $(N=23)$ and healthy controls $(N=18)$ using a processdissociation procedure in a computerized spatial memory task. As expected, the patients performed substantially worse on the conscious memory measures but showed even slightly stronger effects of unconscious influences than the controls. Moreover, a delayed test administered after 1 week revealed a strong decline in conscious influences in the patients, while unconscious influences were not affected. The presented results suggest that conscious and
\end{abstract}

A. Postma $(\bowtie) \cdot R$. Antonides

Experimental Psychology, Helmholtz Institute,

Utrecht University, Heidelberglaan 2, 3584 CS Utrecht,

The Netherlands

e-mail: a.postma@uu.nl

\section{A. J. Wester}

Korsakoff Clinic, Vincent van Gogh Institute for Psychiatry,

Venray, The Netherlands

R. P. C. Kessels

Nijmegen Institute for Cognition and Information,

Radboud University Nijmegen, Nijmegen, The Netherlands

R. P. C. Kessels

Departments of Medical Psychology and Geriatric Medicine, Radboud University Nijmegen Medical Centre,

Nijmegen, The Netherlands

R. P. C. Kessels

Donders Centre for Neuroscience, Radboud University

Nijmegen Medical Centre, Nijmegen, The Netherlands unconscious influences of spatial memory can be clearly dissociated in Korsakoff's syndrome.

Keywords Spatial memory ·

Implicit and explicit memory · Amnesia .

Korsakoff's syndrome

\section{Introduction}

Object-location memory is one of the commonest types of spatial memory. Everyday we need to locate personal items such as glasses, keys or wallets. The process of finding an object in its usual environment may be guided both consciously and unconsciously. We can, for instance, intentionally evoke a vivid recollection of where we have last seen the object but we may also, without being aware of the underlying reason, seemingly automatically start searching in the right place. Hasher and Zacks (1979) already made the distinction between conscious and unconscious processing of spatial information three decades ago. They argued that because of its ecological significance spatial memory encoding progresses mainly or even fully automatically, that is, without direct attention and intent. More recently, Caldwell and Masson (2001) separated unconscious from conscious retrieval of objectlocation information in young and older adults. Among other observations they reported that, relative to the younger participants, conscious recall in the older adults was inferior while their unconscious memory functions appeared intact, suggesting this ability had not deteriorated with age.

In general, implicit memory seems less susceptible to cognitive deterioration resulting from aging or neurological disease than explicit memory (Light and Singh 1987; 
Fleishman and Gabrieli 1997). Furthermore, psychopharmacological drugs have been shown to depress measures of conscious recollection, free recall and recognition but not of familiarity-based recognition or primed fragment completion (Curran et al. 1993; Mintzer and Griffiths 1999). Much less is known, though, about the neurocognitive basis of implicit spatial memory. Chun and Phelps (1999) showed that the implicit mastery of spatial displays in a visual search task was diminished in patients with hippocampal lesions. In contrast, Manns and Squire (2001) demonstrated normal implicit learning on a similar task in a group of patients with lesions that were focal and restricted to the hippocampal region. Moreover, Kessels et al. (2005) observed that, in comparison to explicit memory, implicit spatial memory functions in cortical dementia (i.e., Alzheimer's disease predominantly affecting the medial temporal lobe) were spared. Given these controversies, we deemed it particularly interesting to directly compare conscious and unconscious influences of spatial memory in patients with Korsakoff's syndrome, that is, amnesic patients with lesions in the subcortical areas, using Jacoby's $(1991,1998)$ process-dissociation procedure (PDP) adapted for object-location memory (Caldwell and Masson 2001).

Patients with amnesia due to Korsakoff's syndrome typically have damage to diencephalic regions, more specifically the mammillary bodies and the thalamus, which damage is accompanied by cortical atrophy, predominantly in the prefrontal cortex, due to chronic alcohol abuse and malnutrition (Kopelman 2002; Mayes 1988). It is exactly these areas that are thought to be critical for episodic memory and contextual binding. Arguably, this would also include spatial memory and the binding of objects to their locations. There indeed is abundant evidence for substantial spatial memory impairments in Korsakoff patients (Holdstock et al. 2000; Kessels et al. 2000; Mayes et al. 1991; Shoqeirat and Mayes 1991; Van Asselen et al. 2005). The context-memory deficit hypothesis claims that contextual memory (e.g., recalling object locations) is disproportionally affected in Korsakoff's syndrome compared to target memory (e.g., recalling object identities; Mayes 1988). The question is to what extent this also applies to the implicit retrieval of contextual memory attributes, in other words to implicit types of spatial memory.

In his pioneering case description of a Korsakoff patient Claparède (1907) is one of the first to mention intact implicit memory to coincide with impaired explicit memory. Conclusions in more recent research on implicit memory functions in Korsakoff's syndrome are quite mixed, however, some studies showed spared implicit memory in tasks priming semantic relations between lexical items (Verfaellie et al. 1990), word-completion tests and tasks priming category exemplars (Graf et al. 1985; Levy et al. 2004; Phaf et al. 2000) while other authors reported impaired implicit memory performance in conceptually driven or picturenaming priming tasks (Brunfaut and d'Ydewalle 1996; Verfaellie et al. 1996). Interestingly, in their study comparing controls and Korsakoff patients Verfaellie et al. (1992) demonstrated weaker priming effects for the patients on a task presumably reflecting implicit memory for abstract spatial configurations that could not be verbalized.

The aforementioned findings clearly illustrate that observations of spared implicit memory performance in amnesic patients critically depend on the nature of the task used. There are various other examples in the literature of amnesic patients failing on one type of implicit memory but performing normally on the other. This is often explained by assuming that in the latter case the controls were able to further improve their performance by effectively applying explicit memory strategies. Most notably, Levy et al. (2004) reported corresponding (conceptually driven) priming performance outcomes in their amnesic patients and healthy controls while the declarative recognition scores for the patients were at chance level, suggesting a strict independence of the two memory indices. In the present study we accordingly control for the possibility of mutual interactions between conscious and unconscious memory influences. Ostergaard (1999) proposed an alternative explanation by suggesting that the priming tasks administered might have been too easy and that participants hence relied more on perceptual than on memory factors, allowing amnesic patients to also perform relatively well. He concluded that for any type of memory primed in the prior study phase to have an impact, the inherent difficulty of the task should be carefully considered. Somewhat differently, Gooding et al. (2000) suggested that it is implicit memory for novel information in particular that will show impairments while memory for familiar material tends to be spared.

In the present study the participants were first instructed to place pictures of everyday objects that were presented on a computer screen in appropriate locations in a natural environment (i.e., pictures of various rooms) and memorize the locations. During a subsequent test they were again shown the objects and the original scene but now with three optional locations. Consistent with the aforementioned PDP participants had to relocate half of the objects in their designated locations during the Include condition and the other half in a different location, that is, the Exclude condition. In the former condition, conscious and unconscious influences of spatial memory are supposed to strengthen each other whereas in the latter condition they conflict. In addition to comparing the effects of conscious and unconscious influences on the immediate recall of spatial memory of Korsakoff patients with those in healthy volunteers, we examined the same measures after a 1-week delay as it has 
been argued that conscious memory functions are particularly prone to decline over time. The reverse is assumed for unconscious spatial memories, that is, that they might be less susceptible to neurodegenerative processes and decay over time, although findings are inconclusive. Cave (1997), for example, obtained substantial picture-naming priming effects for periods of 48 weeks and over. Mitchell (2006) even showed picture-fragment identification priming 17 years after the initial exposure. Squire et al. (1987), in contrast, argue that priming effects for certain types of material only persist for a relatively short period. Whether amnesic individuals such as Korsakoff patients show spared implicit memory capacities over time is, again, likely to depend on the type of task used (McAndrews et al. 1987; Squire et al. 1987). Using a comparable PDP with verbal material Kopelman and Stanhope (1997) observed levels of conscious forgetting in Korsakoff patients over a 30-min retention interval that resembled the levels observed in their control subjects. Unconscious memory effects in the patients were, moreover, substantial.

\section{Methods}

\section{Participants}

Twenty-three inpatients, of whom five were women, residing in the Korsakoff clinic of the Vincent van Gogh Institute, Venray, the Netherlands, all having been diagnosed with chronic Korsakoff's syndrome within one to six months prior to testing, participated in the study. All fulfilled the criteria for DSM-IV Alcohol-Induced Persisting Amnestic Disorder (American Psychiatric Association 1994) and for Korsakoff's syndrome as described by Kopelman (2002) and all had an extensive history of alcoholism and nutritional depletion, notably thiamine deficiency, as verified on the basis of medical charts or family reports. None of the patients fulfilled the clinical criteria for alcohol dementia (Oslin et al. 1998). Eighteen healthy volunteers matched for age, sex and education were recruited from the general public and also screened. The mean age of the patients and the controls was 52.8 years (SD 7.3 and 6.8, respectively). Classified on a 7-point scale, with one reflecting little to no training (less than primary school) and seven the highest obtainable educational level (academic degree), the mean educational level for the Korsakoff patients was $4.3(\mathrm{SD}=1.4)$ and for the controls $4.9(\mathrm{SD}=1.1)$. The mean handedness scores as measured by the Dutch version of the Annett Handedness Inventory (Annett 1970) were 19.4 (SD = 9.6) for the patients and 19.2 ( $\mathrm{SD}=9.1)$ for the controls. The groups were comparable as to their demographics and handedness. Neuroradiological reports (CT or MRI) were available for
22 patients; 15 patients showed signs of supra- or infratentorial atrophy and in two patients vascular lesions were reported; five patients showed no visible neuroradiological abnormalities (see Table 1). Although signs of brain atrophy and non-specific white-matter lesions are common in Korsakoff patients, these are not necessary criteria for the diagnosis (Kopelman 2002).

With respect to general cognitive ability, the patients were severely impaired on word-list learning [the Dutch version of the California Verbal Learning Test (CVLT); Delis et al. 1987] which can be regarded as a test for item memory. The scores of 17 of the 18 patients for whom test results were available were two or more SDs below the normative mean on standardized immediate reproduction. Twelve of the 21 patients performing the Tower of London Test (Shallice 1982) as an index for executive functioning had scores of two or more SDs below the normative mean.

All participants gave their informed consent prior to their participation. The experiment was approved by the local medical ethics committee and conducted in accordance with the Helsinki Declaration.

\section{Materials}

The Rooms Task, adapted from Caldwell and Masson (2001) and Kessels et al. (2005), was run on a Pentium PC and responses were monitored using a $15^{\prime \prime}$ LCD touch screen. In a separate short panel study a group of healthy participants that were not part of the succeeding study were asked to assign each of 50 digital $(5 \times 5 \mathrm{~cm})$ color pictures depicting an everyday object that were presented at the bottom of the screen to the most probable location of a large number of alternatives within the $(20 \times 25 \mathrm{~cm})$ photographs of one of five rooms (ten objects per room; living room, bedroom, study, bathroom and kitchen; see Fig. 1 for a schematic overview of the task). Based on these assignments three likely target locations for each object were selected for the actual experimentation phase, that is, never the least nor the most frequently chosen (the least or most appropriate) sites. Two of the locations served as the distractors in the recognition test. The possible locations for an object in the room photographs were indicated by empty squares. After the participant had indicated the correct position by touching the location on the screen, a $2 \times 2 \mathrm{~cm}$ picture of the object appeared at the identified location.

\section{Procedure}

During the learning phase of the experiment, in each of 40 trials a photograph of a room and an picture of an object were shown, with an empty square marking the object's target location. Participants had to place each object in the 
Table 1 Data on the handedness, age, sex, educational level, radiological and neuropsychological backgrounds of the Korsakoff patients

\begin{tabular}{|c|c|c|c|c|c|c|c|c|}
\hline Patient & Handedness $^{\mathrm{a}}$ & Age & Gender & Education $^{\mathrm{b}}$ & Brain scan & Radiological findings & $\begin{array}{l}\text { CVLT } \\
\text { Scores }^{c}\end{array}$ & $\begin{array}{l}\text { Tower of } \\
\text { London }^{\text {d }}\end{array}$ \\
\hline 1 & 19 & 50 & M & 5 & $\mathrm{CT}$ & Cortical and cerebellar atrophy & -4 & 17 \\
\hline 2 & 13 & 42 & $\mathrm{~V}$ & 4 & $\mathrm{CT}$ & Cortical and cerebellar atrophy & -7 & 25 \\
\hline 3 & 24 & 50 & M & 5 & $\mathrm{CT}$ & Cortical atrophy & -8 & 19 \\
\hline 4 & 24 & 59 & M & 5 & $\mathrm{CT}$ & Mild cerebellar atrophy & & \\
\hline 5 & 17 & 49 & M & 5 & $\mathrm{CT}$ & Cortical and cerebellar atrophy & -7 & 23 \\
\hline 6 & 20 & 46 & V & 2 & $\mathrm{CT}$ & No abnormalities & -8 & 17 \\
\hline 7 & 24 & 61 & M & 2 & $\mathrm{CT}$ & No abnormalities & & \\
\hline 8 & 24 & 49 & M & 2 & MRI & Multiple vascular lesions & -8 & 22 \\
\hline 9 & 20 & 64 & $\mathrm{~V}$ & 6 & $\mathrm{CT}$ & Cortical atrophy & -4 & 20 \\
\hline 10 & 20 & 55 & M & 5 & MRI & Mild cortical atrophy & -4 & 32 \\
\hline 11 & 24 & 42 & M & 5 & $\mathrm{CT}$ & Mild cerebellar atrophy and left frontal vascular lesion & -4 & 28 \\
\hline 12 & 24 & 66 & M & 5 & $\mathrm{CT}$ & Left temporal vascular lesion & & 28 \\
\hline 13 & 24 & 60 & M & 2 & $\mathrm{CT}$ & Cerebellar atrophy & & 20 \\
\hline 14 & 8 & 43 & $\mathrm{~V}$ & 4 & MRI & Cerebellar atrophy & -8 & 29 \\
\hline 15 & 24 & 52 & M & 5 & $\mathrm{CT}$ & No abnormalities & & 23 \\
\hline 16 & 24 & 49 & M & 5 & $\mathrm{CT}$ & Cortical and infratentorial atrophy & -5 & 16 \\
\hline 17 & 24 & 55 & $\mathrm{~V}$ & 3 & $\mathrm{CT}$ & Cortical and infratentorial atrophy & -7 & 34 \\
\hline 18 & 24 & 67 & M & 5 & $\mathrm{CT}$ & Mild cerebellar atrophy & -3 & 27 \\
\hline 19 & 19 & 49 & $\mathrm{M}$ & 5 & $\mathrm{CT}$ & Cortical and infratentorial atrophy & -5 & 32 \\
\hline 20 & 17 & 56 & M & 5 & $\mathrm{CT}$ & Mild cortical atrophy & -5 & 31 \\
\hline 21 & 24 & 50 & M & 5 & NA & & -5 & 19 \\
\hline 22 & -20 & 53 & M & 6 & MRI & No abnormalities & -6 & 20 \\
\hline 23 & 24 & 48 & $\mathrm{M}$ & 2 & MRI & Subcortical atrophy & -4 & 31 \\
\hline
\end{tabular}

$C T$ computer tomography, MRI magnetic resonance imaging, $N A$ not available

${ }^{\text {a }}$ Scores on the Dutch version of the Annett Handedness Inventory; -24 to -8 is left-handed; -8 to 8 is mixed-handed; 8 to 24 is right-handed

${ }^{\mathrm{b}}$ Educational levels scored using 7 categories with 1 indicating little or no formal training and 7 one or more university degrees

${ }^{c}$ Dutch version of the California verbal learning test (CVLT), immediate reproduction over five consecutive presentations (standardized scores for age and sex, mean in norm population is $0, \mathrm{SD}=2$ )

d Tower of London test (in a comparable reference group mean was 30.6, SD = 2.7)

designated location and were instructed to memorize each of the locations for a test they would be taking later afterward. As recommended by Caldwell and Masson (2001), all participants had to say the name of all 40 objects and their designated locations out loud to help the Korsakoff patients focus their attention on the relevant features of the task. While no time limits were imposed for memorizing the individual objects, all participants completed the trial series at a constant rate of about $3 \mathrm{~s}$ per object. The order in which the objects were presented was randomized over participants both during the memorizing stage and the succeeding recognition test.

The Korsakoff patients took the recognition test after a 1-min break while the controls did so after $15 \mathrm{~min}$, which latter interval was chosen to avoid ceiling-performance effects. All participants completed a test trial in which three empty squares in the room photograph indicated possible locations (i.e., the target location and two distractor locations) for the object presented at the bottom of the screen. In each of the 50 experimental trials, one of two instructions, that is, Include or Exclude, was shown at the bottom of the screen and read out loud by the experimenter. The participants were presented 25 trials in each condition to which the objects had been randomly assigned. The order in which the objects were presented was again randomized and different from the order in the learning phase. Note that ten of the objects (five in each condition and all randomly selected per participant) in the recognition test were new in that they had not been shown in the learning phase. These new objects served to estimate chance performance, that is, the number of times a participant chose pre-assigned target locations during the recognition test without having earlier memorized the particular objectlocation pair. 
Fig. 1 Schematic overview of the rooms task (actual picture size approx. $20 \times 25 \mathrm{~cm}$ ) during the learning and the test phase. In the Include trials (a) of the test participants had to relocate the objects to the positions they had occupied previously while in the Exclude trials (b), they needed to allocate the object to a different location (choice of three). In case the original location could not be remembered, in both conditions participants had to place the object in the first location that came to mind. Objects that had not been shown during the learning phase were introduced to determine chance performance (c)
Learning phase

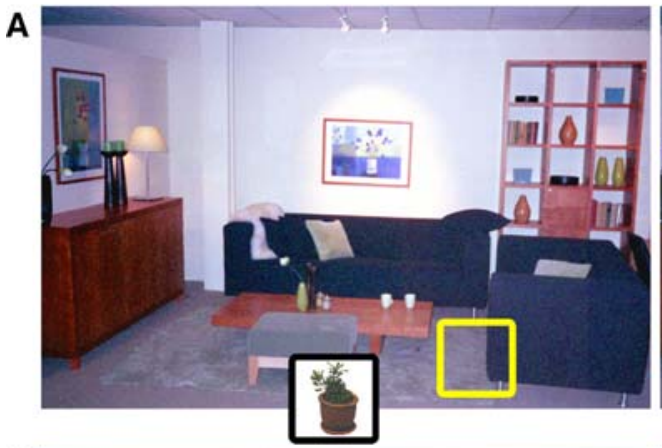

B

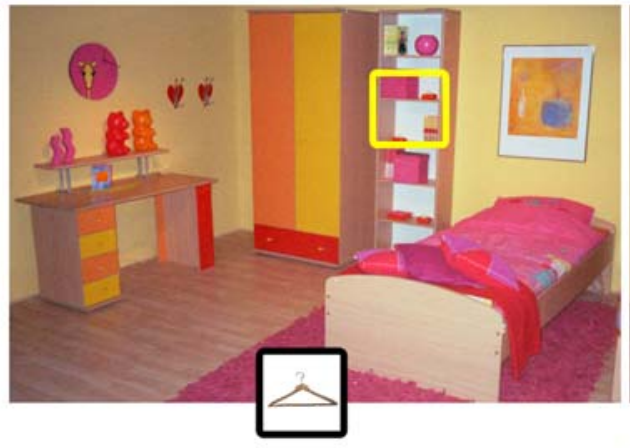

Test phase
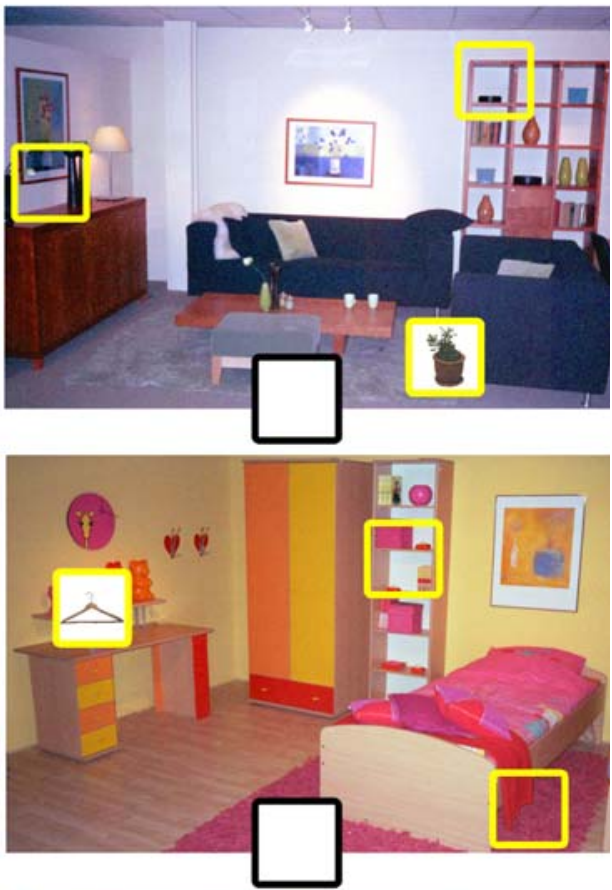

C

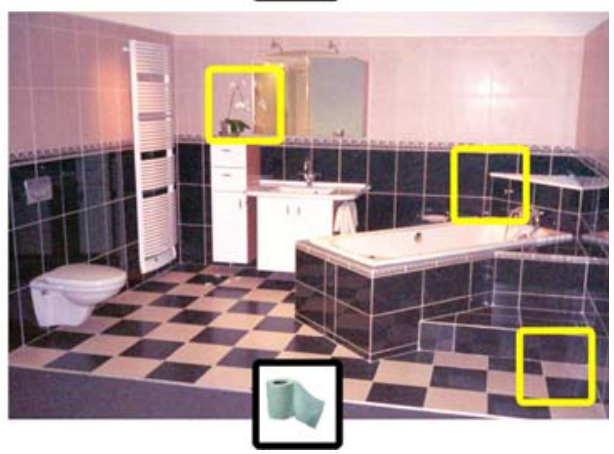

For the Include trials the participants were instructed to place the object in its original location. In case they failed to recollect the position, participants were instructed to allocate the object to the first location that came to mind, in which case their choice might reflect unconscious memory influences. Thus, in the Include trials both conscious and unconscious influences of memory might help produce the correct answer, that is, the object's designated location. In the Exclude trials, the participants were first asked to recall the object's original location and to subsequently place the object at a different one. Again, conscious recollection of the original event was required. However, when they failed to recall the original position, participants were again prompted to assign the object to the first location that came to mind. Here, unconscious memory influences might still make them select the original site, thus violating the instructions in this condition. Finally, both the patients and the controls took the same recognition test 1 week after the first test.
The percentage of objects placed in their original target locations allows the conscious and unconscious influences of memory to be estimated (see Eq. 1) for both conditions: Include Trials : $\mathrm{P}($ targets $)=\mathrm{C}+(1-\mathrm{C}) \mathrm{U}$

Exclude Trials : $\mathrm{P}($ targets $)=(1-\mathrm{C}) \mathrm{U}$

with $\mathrm{C}$ reflecting the conscious influence and $\mathrm{U}$ the unconscious influence (Caldwell and Masson 2001). The probabilities of selecting the designated target locations, the $\mathrm{C}$ and $\mathrm{U}$ estimates, and chance levels were computed for each participant separately.

\section{Results}

We first conducted analyses of variance to determine the general probability of selecting the designated target locations for the two conditions separately (i.e., the percentage of correct answers in the Include and the 
percentage of errors in the Exclude condition), with Group (Patient vs. Controls) as the between-subjects factor and Delay [Immediate vs. Delayed (1-week) Recall] as the within-subject factor (see Table 2). Both the Include and the Exclude condition yielded significant effects both for Group $(F[1,39]=42.5, P<0.01$ and $F[1,39]=41.1, P<$ 0.01 , respectively) and for Delay $(F[1,39]=38.5, P<0.01$ and $F[1,39]=20.1, P<0.01$, respectively). Table 2 shows that overall the probability of choosing the original locations was lower after the 1-week delay with lower rates for the Korsakoff group in the Include condition. For the Exclude condition the reverse trend was observed. The interaction between Group and Delay was not significant for either condition (Include: $F[1,39]=1.63, P=0.21$; Exclude: $F[1,39]=0.79, P=0.41)$.

The PDP methodology assumes independence of conscious and unconscious influences of memory. To verify this assumption, the percentage of the new objects in which the pre-assigned target location was chosen was computed. For the immediate recall test the independence assumption was confirmed in that no significant differences emerged between conditions $(F[1,39]=1.76, P=0.19)$ or groups $(F[1,39]=0.61, P=0.44)$ and no interaction effect $(F[1$, 39 ] $=0.04, P=0.84$ ) was found (percentages were 0.23 and 0.27 in the Include and 0.29 and 0.31 in the Exclude condition for patients and controls, respectively). For the 1week delay there was a marginally significant difference between the conditions $(F[1,39]=3.99, P=0.053)$ but again no significant group difference emerged $(F[1,39]=$ $2.74, P=0.11)$ nor an interaction effect $(F[1,39]=1.6, P=$ 0.21 ) (with percentages of 0.17 and 0.30 in the Include and 0.32 and 0.33 in the Exclude condition for the patients and controls, respectively).

Figure 2 shows the $\mathrm{C}$ (conscious influence of memory) and $\mathrm{U}$ (unconscious influence of memory) estimates. Two 2 $\times 2$ ANOVAs were performed for $\mathrm{C}$ and $\mathrm{U}$ separately, including Delay as the within-subject factor and Group as the between-subjects factor. The controls had strongly outperformed the patients on the conscious memory estimates, $\mathrm{C}(F[1,39]=84.4, P<0.01)$. Delay also yielded a significant effect for the conscious memory scores $(F[1$, $39]=63.5, P<0.01)$. The outcomes on the unconscious influences of memory were even slightly better in the patient group $(F[1,39]=5.13, P=0.029)$ but they were not affected by delay.

To determine whether the $U$ estimates reflected true memory influences rather than pre-existing preferences to place objects at particular locations within specific rooms, we compared $U$ against chance estimates. Because of the low number of 'new-object' trials $(n=5)$ in each condition, we decided to collapse their data as well as those of the immediate and the delayed recall conditions. Interestingly, the patients' unconscious memory scores (averaged over the immediate and delayed trials) were significantly higher than their chance levels (the percentage that the designated target location was chosen for the new items, again averaged over the immediate and delayed trials), $t[22]=2.7, P$ $=0.014)$, while the unconscious scores of the controls were not $(t[17]=1.7, P=0.16)$. Chance levels did not differ between groups $(t[39]=1.8, P=0.074$, with chance being $0.25 \pm 0.1$ for the patients and $0.31 \pm 0.1$ for the controls).

\section{Discussion}

With our experiment we sought to compare the conscious and unconscious spatial memory estimates of patients with Korsakoff amnesia and healthy matched controls as derived from the process-dissociation procedure (PDP) developed by Jacoby $(1991,1998)$ and adapted by Caldwell and Masson (2001) for object-location memory. The comparison revealed a twofold dissociation between conscious and unconscious influences of spatial memory in the patients and the controls. The patients appeared to have a poor conscious memory of object locations in their natural surroundings. Yet, and strikingly, they performed slightly better than the controls on unconscious spatial memory, showing that unconscious and conscious influences of spatial memory are functionally distinct. Caldwell and Masson (2001) provided evidence in the same direction by demonstrating that aging had distinct effects on the two memory scores.

Our evidence of spared unconscious memory influences in Korsakoff patients supports several other studies reporting normal implicit memory performance (Graf et al. 1985; Phaf et al. 2000; Verfaellie et al. 1990; Fama et al.

Table 2 Mean probabilities ( $+\mathrm{SD}$ ) of choosing the original (designated) target locations in the Include and Exclude conditions of the recognition test for the immediate recall and the 1-week delay for the amnesic Korsakoff patients and the healthy controls

\begin{tabular}{|c|c|c|c|c|}
\hline \multirow[t]{2}{*}{ Probability original locations } & \multicolumn{2}{|c|}{ Amnesia patients } & \multicolumn{2}{|l|}{ Controls } \\
\hline & Immediate & After 1 week & Immediate & After 1 week \\
\hline Include condition & $0.41(0.12)$ & $0.30(0.12)$ & $0.64(0.12)$ & $0.48(0.12)$ \\
\hline Exclude condition & $0.25(0.11)$ & $0.35(0.08)$ & $0.13(0.07)$ & $0.19(0.08)$ \\
\hline
\end{tabular}



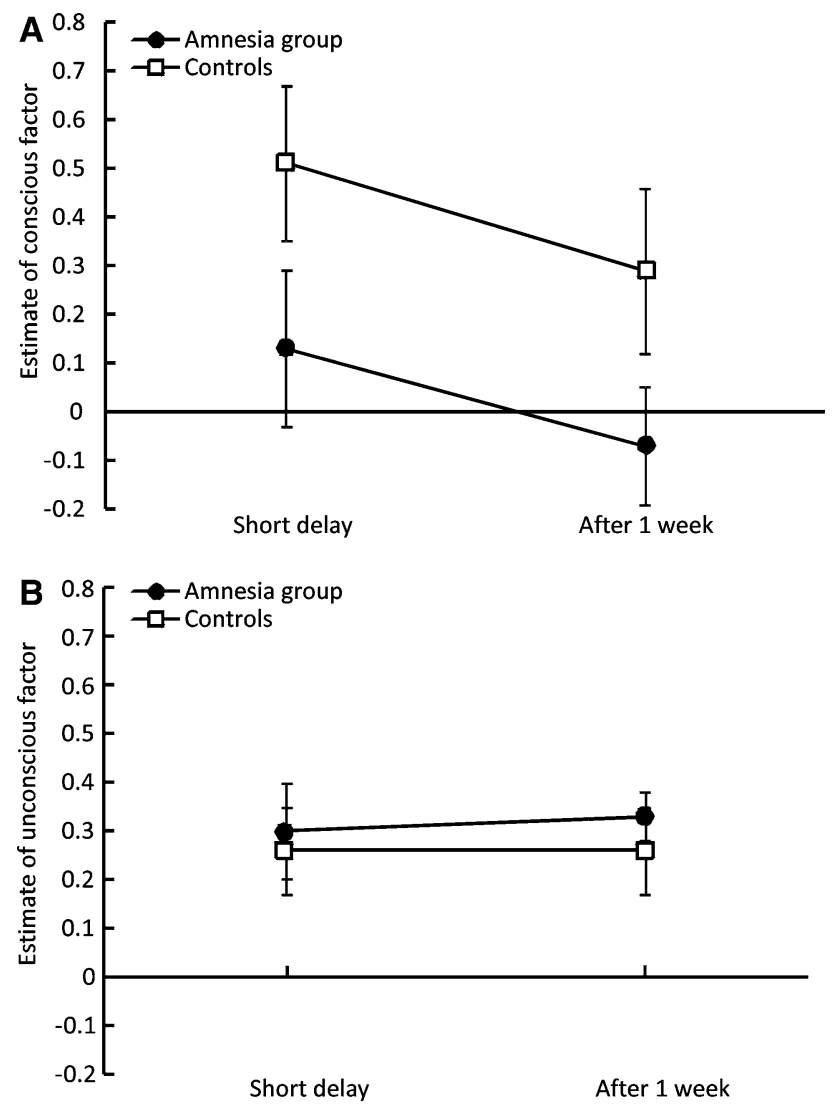

Fig. 2 Estimates of conscious (a) and unconscious (b) memory influences for the Korsakoff amnesia patients and the controls in the immediate recall and the delayed recall conditions

2006) although it contradicts other investigations (Brunfaut and d'Ydewalle 1996; Verfaellie et al. 1996, 1992). The disparate observations on implicit memory performance in amnesics in the literature seem to indicate that the presence or absence of any difference with normal healthy volunteers critically depends on the type of task that is used and the subform of implicit memory that is being studied (see also Gooding et al. 2000; Ostergaard 1999). The task we employed assessed the ability of Korsakoff amnesics and controls to commit spatial information about natural scenes resembling familiar, everyday situations to memory. Because of its clear ecological relevance, unconscious, automatic retrieval of this type of information could indeed be boosted given the right circumstances and it, moreover, appears to be less susceptible for cognitive deterioration due to both cortical and subcortical brain damage.

The controls having inferior unconscious memory estimates than the Korsakoff patients seems counterintuitive, but we wish to point out that these estimates were only above chance in the Korsakoff group and not in the controls, complicating interpretation of the controls' unconscious memory scores. Their scores may be underestimates because the controls tended to engage in strategic contemplation when they found themselves unable to recollect an item's original location. Jacoby (1991, 1998) argues that the process-dissociation procedure works best if one simply chooses the first possibility that comes to mind when no conscious recollection is available. A response manner in which options are checked and choices strategically made is likely to increase the chance of old locations being excluded, resulting in underestimations of U (Curran and Hintzman 1995). Of particular importance here could be the fact that Korsakoff patients are known to suffer executive deficits (Brand 2007) that clearly hamper the ability to employ efficient strategic behaviors in cognitive tests. It is very likely that for these reasons the patients in our study displayed a more direct 'first coming to mind' strategy than the controls. While we cannot unequivocally conclude that Korsakoff patients show stronger unconscious influences of memory than healthy controls, our data clearly indicate that Korsakoff patients maintain some form of residual spatial learning and/or retrieval in the absence of adequate conscious recollection.

Of further interest, we showed that recognition after a prolonged delay yielded distinct effects on the conscious and unconscious influences of memory. Conscious memories had strongly deteriorated after a week, with the patients displaying a decline comparable to that of their healthy peers. This could suggest that the main deficit in Korsakoff patients involves the encoding of rich contextual memory traces, which can be consciously recollected at a later time. The well-recorded damage to diencephalic structures in Korsakoff's disease may be crucial here, in analogy with the pattern observed by Kopelman and Stanhope (1997) during a verbal memory task: in contrast to the conscious estimates, unconscious influences of memory persisted over time.

A methodological issue warranting discussion involves the fact that the immediate retention interval was not equal for our two groups. We tested the Korsakoff patients one minute after the presentation phase, whereas the controls were tested after a 15-min delay. Similar procedures are frequently employed to avoid ceiling effects and to normalize the performance levels of patients and controls. One may, for instance, simplify the material (see Chalfonte et al. 1996), lengthen the presentation time (Kopelman and Stanhope 1997; Kopelman et al. 1997) and shorten the delay (MacAndrew and Jones 1993). In our case one might argue that the shorter retention interval in the immediate recall condition may have given the Korsakoff patients an advantage over the controls, explaining the patients' superior implicit memory scores. However, this is unlikely given our observations of a general invariance of implicit memory over time. Moreover, at the 1-week delay 
retention intervals were equal for patients and controls, with the Korsakoff patients still showing stronger unconscious memory influences.

It should be mentioned that the PDP methodology has had its fierce critics (Curran and Hintzman 1995; Graf and Komatsu 1994; Joordens and Merikle 1993). In reply, Jacoby and colleagues (Jacoby 1998; Jacoby et al. 1997) further specified the boundary conditions for an optimal use of the PDP. In a comparable spatial memory task as the one we used, Caldwell and Masson (2001) further verified the validity of the PDP and the independence of the conscious and unconscious memory estimates by applying a direct-retrieval version of the multinomial model developed by Buchner et al. (1995) and Jacoby (1998).

The substantial decline in conscious spatial memory performance in our sample of Korsakoff patients is in general accordance with the existing literature on spatial memory in patients with cortical or subcortical lesions. Besides the diencephalic circuit, the hippocampal formation, a structure that plays an important role in context memory and is typically associated with cognitive mapping of space and explicit spatial memory, is also implicated in Korsakoff's syndrome (Chalfonte et al. 1996; Colchester et al. 2001; Paller et al. 1997; Reed et al. 2003; Visser et al. 1999). Although spatial memory impairments are known to occur after hippocampal lesions in particular (Kessels et al. 2001, 2004; Maguire et al. 2000; O'Keefe and Nadel 1978; Spiers et al. 2001), to what extent the damage also affects unconscious memory influences is, as yet, unclear. As mentioned in the "Introduction", Chun and Phelps (1999) showed that the implicit learning of spatial displays in their visual search task was diminished in patients with hippocampal lesions, whereas Manns and Squire (2001) found no such evidence. It thus remains to be seen whether the hippocampus is indeed involved in implicit spatial memory processes and whether it applies to the implicit mastery of relative complex spatial configurations in particular. Possibly, the formation of simple object-location relations might be spared at the implicit level.

In conclusion, with the present study we have shown that the neurocognitive bases of conscious and unconscious influences of object-location memory clearly differ. Amnesic patients with Korsakoff's syndrome demonstrate only weak conscious influences of memory for spatial information while unconscious influences are spared. Future studies will need to investigate whether spatial information is typically processed unconsciously and which particular neural circuitries are involved.

Acknowledgments The research reported here was supported by grants from the Netherlands Organization for Scientific Research (NWO: 440-20-000) and by EU NEST Fp6 grant (No 12959Wayfinding). We also thank Mrs. Hanneke Meulenbroek-van der Meulen for her detailed comments on the manuscript.
Open Access This article is distributed under the terms of the Creative Commons Attribution Noncommercial License which permits any noncommercial use, distribution, and reproduction in any medium, provided the original author(s) and source are credited.

\section{References}

American Psychiatric Association (1994) Diagnostic and statistical manual of mental disorders, 4th edn, Washington DC

Annett M (1970) A classification of hand preference by association analysis. Br J Psychol 61:303-321

Brand M (2007) Cognitive profile of patients with alcoholic Korsakoff's syndrome. Int J Disabil Hum Dev 6:161-170

Brunfaut E, d'Ydewalle G (1996) A comparison of implicit memory tasks in Korsakoff and alcoholic patients. Neuropsychologia 34:1143-1150

Buchner A, Erdfelder E, Vaterrodt-Plunnecke B (1995) Toward unbiased measurement of conscious and unconscious memory processes within the process dissociation framework. J Exp Psychol Gen 124:137-160

Caldwell JI, Masson ME (2001) Conscious and unconscious influences of memory for object location. Mem Cognit 29:285-295

Cave CB (1997) Very long-lasting priming in picture naming. Psychol Sci 8:322-325

Chalfonte BL, Verfaellie M, Johnson MK, Reiss L (1996) Spatial location memory in amnesia: binding item and location information under incidental and intentional encoding conditions. Memory 4:591-614

Chun MM, Phelps EA (1999) Memory deficits for implicit contextual information in amnesic subjects with hippocampal damage. Nat Neurosci 2:844-847

Claparède ED (1907) Expériences sur la mémoire dans un cas de psychose de Korsakoff. Rev Med Suisse Romande 27:301-303

Colchester A, Kingsley D, Lasserson D, Kendall B, Bello F, Rush C, Stevens TG, Goodman G, Heilpern G, Stanhope N, Kopelman MD (2001) Structural MRI volumetric analysis in patients with organic amnesia, 1: methods and comparative findings across diagnostic groups. J Neurol Neurosurg Psychiatry 71:13-22

Curran HV, Gardiner JM, Java RI, Allen D (1993) Effects of lorazepam upon recollective experience in recognition memory. Psychopharmacology 110:374-378

Curran T, Hintzman DL (1995) Violations of the independence assumption in process dissociation. J Exp Psychol Learn Mem Cognit 21:531-547

Delis DC, Kramer JH, Kaplan E, Ober BA (1987) California verbal learning test (CVLT): adult version. Psychological Corporation, San Antonio

Fleishman DA, Gabrieli JDE (1997) Repetition priming in normal aging and Alzheimer's disease: a review of findings and theories. Psychol Aging 13:88-119

Fama R, Pfefferbaum A, Sullivan EV (2006) Visuoperceptual learning in alcoholic Korsakoff syndrome. Alcohol Clin Exp Res 30:680-687

Gooding PA, Mayes AR, van Eijk R (2000) A meta-analysis of indirect memory tests for novel material in organic amnesics. Neuropsychologia 38:666-676

Graf P, Komatsu S (1994) Process dissociation procedure: handle with caution!. Eur J Cognit Psychol 6:113-129

Graf P, Shimamura AP, Squire LR (1985) Priming across modalities and priming across category levels: extending the domain of preserved function in amnesia. J Exp Psychol Hum Learn $11: 386-396$ 
Hasher L, Zacks RT (1979) Automatic and effortful processes in memory. J Exp Psychol Gen 108:356-388

Holdstock JS, Mayes AR, Cezayirli E, Isaac CL, Aggleton JP, Roberts N (2000) A comparison of egocentric and allocentric spatial memory in a patient with selective hippocampal damage. Neuropsychologia 38:410-425

Jacoby LL (1991) A process-dissociation framework: separating automatic from intentional uses of memory. J Mem Lang 30:513-541

Jacoby LL (1998) Invariance in automatic influences of memory: toward a user's guide for the process-dissociation procedure J Exp Psychol Learn Mem Cognit 24:3-26

Jacoby LL, Yonelinas AP, Jennings JM (1997) The relation between conscious and unconscious (automatic) influences: a declaration of independence. In: Cohen JD, Schooler JW (eds) Scientific approaches to consciousness. Erlbaum, Mahwah, pp 13-47

Joordens S, Merikle PM (1993) Two models of conscious and unconscious influences. J Exp Psychol Gen 122:462-467

Kessels RPC, de Haan EHF, Kappelle LJ, Postma A (2001) Varieties of human spatial memory: a meta-analysis on the effects of hippocampal lesions Brain Res Rev 35:295-303

Kessels RPC, Feijen J, Postma A (2005) Implicit and explicit memory for spatial information in Alzheimer's disease. Dement Geriatr Cogn Disord 20:184-191

Kessels RPC, Hendriks MPH, Schouten J, Van Asselen M, Postma A (2004) Spatial memory deficits in patients after unilateral selective amygdalohippocampectomy. J Int Neuropsychol Soc 10:907-912

Kessels RPC, Postma A, Wester AJ, de Haan EHF (2000) Memory for object locations in Korsakoff's amnesia. Cortex 36:47-57

Kopelman MD (2002) Disorders of memory. Brain 125:2152-2190

Kopelman MD, Stanhope N (1997) Rates of forgetting in organic amnesia following temporal lobe, diencephalic, or frontal lobe lesions. Neuropsychol 11:343-356

Kopelman MD, Stanhope N, Kingsley D (1997) Temporal and spatial context memory in patients with focal frontal, temporal lobe and diencephalic lesions. Neuropsychologia 35:1533-1545

Levy DA, Stark CEL, Squire LR (2004) Intact conceptual priming in the absence of declarative memory. Psychol Sci 15:680-686

Light LL, Singh A (1987) Implicit and explicit memory in young and older adults. J Exp Psychol Learn Mem Cognit 4:531-541

MacAndrew SB, Jones GV (1993) Spatial memory in amnesia: evidence from Korsakoff patients. Cortex 29:235-249

Maguire EA, Gadian DG, Johnsrude IS, Good CD, Ashburner J, Frackowiak RS, Frith CD (2000) Navigation-related structural change in the hippocampi of taxi drivers. Proc Natl Acad Sci USA 97:4398-4403

Manns JR, Squire LR (2001) Perceptual learning, awareness and the hippocampus. Hippocampus 11:776-782

Mayes AR (1988) Human organic memory disorders. Cambridge University Press, Cambridge

Mayes AR, Meudell PR, MacDonald C (1991) Disproportionate intentional spatial-memory impairments in amnesia. Neuropsychologia 29:771-784
McAndrews MP, Glisky EL, Schacter DL (1987) When priming persists: long-lasting implicit memory for a single episode in amnesic patients. Neuropsychologia 25:497-506

Mintzer MZ, Griffiths RR (1999) Selective effects of zolpidem on human memory functions. J Psychopharmacol 13:18-31

Mitchell DB (2006) Nonconscious priming after 17 years. Psychol Sci 17:925-929

O'Keefe J, Nadel L (1978) The hippocampus as a cognitive map. Oxford University Press, Oxford

Oslin D, Atkinson RM, Smith DM, Hendrie H (1998) Alcohol related dementia: proposed clinical criteria. Int J Geriatr Psychiatry 13:203-212

Ostergaard AL (1999) Priming deficits in amnesia: now you see them, now you don't. J Int Neuropsychol Soc 5:175-190

Paller KA, Acharya A, Richardson BC, Plaisant O, Shimamura P, Reed BR, Jagust WJ (1997) Functional neuroimaging of cortical dysfunction in alcoholic Korsakoff's syndrome. J Cogn Neurosci 9:277-293

Phaf HR, Geurts H, Eling PA (2000) Word frequency and word stem completion in Korsakoff patients. J Clin Exp Neuropsychol $22: 817-829$

Reed LJ, Lasserson D, Marsden P, Stanhope N, Stevens T, Bello F, Kingsley D, Colchester A, Kopelman MD (2003) FDG-PET findings in the Wernicke-Korsakoff syndrome. Cortex 39:10271045

Shallice T (1982) Specific impairments of planning. Philos Trans R Soc Lond B Biol Sci 298:199-209

Shoqeirat MA, Mayes AR (1991) Disproportionate incidental spatialmemory and recall deficits in amnesia. Neuropsychologia 29:749-769

Spiers HJ, Burgess N, Hartley T, Vargha-Khadem F, O'Keefe J (2001) Bilateral hippocampal pathology impairs topographical and episodic memory but not visual pattern matching. Hippocampus 11:715-725

Squire LR, Shimamura AP, Graf P (1987) Strength and duration of priming effects in normal subjects and amnesic patients. Neuropsychologia 25:195-210

Van Asselen M, Kessels RPC, Wester A, Postma A (2005) Spatial working memory and contextual cueing in patients with Korsakoff amnesia. J Clin Exp Neuropsychol 27:645-655

Verfaellie M, Cermak LS, Blackford SP, Weiss S (1990) Strategic and automatic priming of semantic memory in alcoholic Korsakoff patients. Brain Cognit 13:178-192

Verfaellie M, Gabrieli JD, Vaidya CJ, Croce P, Reminger SL (1996) Implicit memory for pictures in amnesia: Role of etiology and priming task. Neuropsychol 10:517-528

Verfaellie M, Milberg WP, Cermak LS, Letourneau LL (1992) Priming of spatial configurations in alcoholic Korsakoff's amnesia. Brain Cognit 18:34-45

Visser PJ, Krabbendam L, Verhey FR, Hofman PA, Verhoeven WM, Tuinier S, Wester A, Den Berg YW, Goessens LF, Werf YD, Jolles J (1999) Brain correlates of memory dysfunction in alcoholic Korsakoff's syndrome. J Neurol Neurosurg Psychiatry 67:774-778 